\title{
Importance of Non-Store Retailing for Product Exchange in Varna District
}

\author{
Prof. PhD Michal Stojanov \\ University of Economics - Varna, Varna, Bulgaria \\ michal.stojanov@ue-varna.bg
}

\begin{abstract}
The penetration of digital technologies into the ordinary daily life of a person creates a huge sphere of emerging opportunities with its specific and significant economic and social importance. In terms of product exchange, the field of attracting, stimulating and satisfying consumer demand is gradually migrating to the new dimensions of digital technology and the Internet. Today, more and more retailers are successfully adapting information and communication technologies to carry out their businesses into the new economy. This enables their favorable development at global, national and regional levels and the need for systematic studies. The article examines the main economic indicators of the activity of business agents of non-store retail trade in Varna region, which allows to draw a picture of the specific regional development and to look at the background similarities and differences with the processes taking place at national and global level.
\end{abstract}

Keywords: non-store retail trade, e-commerce, district Varna

JEL Code: L81; doi:10.36997/IJUSV-ESS/2019.8.1.47

\section{Въведение}

През изминалите години значимостта на търговията на дребно, осъществявана в извънмагазинни форми, непрекъснато се увеличава, основно под въздействието на разширяващата се популярност на информационно-комуникационните технологии и установяването и разпространението на електронните канали за продуктова размяна. Според прогнозата на eMarketer за електронната търговия на дребно в световен мащаб, тя може да достигне обем от 4,058 трилиона щ. д. през 2020 г., при дял от общите продажби на дребно от 14,6\% и ръст спрямо предходната година от 18,7\% (eMarketer inc., 2016). В тази глобална тенденция все по-съществен ще става и дельт на мобилната търговия, която през 2020 г. ще достигне световен обем от 2,910 трилиона щ. д. при очаквано процентно изменение на годишна база от $22,2 \%$ до величина от 3,556 трилиона щ. д. и дял от електронната тьрговия на дребно от 72,9\% през 2021 г. (eMarketer inc., 2018). Тези данни разкриват позитивно развитие и благоприятни перспективи за глобалното разрастване на електронните форми на търговия на дребно, извършвана извън физически магазини.

Основната цел на настоящата работа е да направи преглед на състоянието и развитието на основни икономически показатели на търговията на дребно извън търговски обекти в област Варна и да очертае възможности за развитие на тази стопанска дейност в бъдеще.

Представените данни за обхванатия в изследването период 2004-2016 г. са обобщени като част от регионалното статистическо наблюдение за област Варна (NUTS 3) на Националния статистически институт и отразяват основни показатели на предприятията в икономическа дейност с код 47.9 „Търговия на дребно извън търговски обекти“ по КИД-2008 (NACE Rev. 2). Тази група включва търговия на дребно чрез поръчки по пощата, Интернет, доставка по домовете, чрез търговски автомати (вендинг), директни продажби и други форми на обмен, реализирани извън търговски обекти, при които купувачът прави своя избор на базата на рекламни брошури, каталози, информация в уеб сайтове и страници, мостри или всякакви други лични и нелични маркетингови комуникационни средства (Eurostat, 2019). Покупките се осъществяват чрез поръчки, извършвани извън търговски обекти и от разстояние, при което може да се прилага пряка и непряка опосредстваща комуникация между участващите страни. Тя може да се реализира посредством съвременни 
информационно-комуникационни технологии, но може да бъде извършвана и с помощта на търговски автомати. За поръчаните „твърди“ продукти се изпълнява физическа доставка, посредством дейността на търговски агенти, пощенски и куриерски оператори, докато за т.нар. „меки“ продукти те могат да бъдат директно получени или изтеглени от Интернет. По този начин посредством традиционни и нови способи, продукт на дигитализационните процеси, в обществото и икономиката се разширяват възможностите за осъществяване на продуктов обмен. При това посредством формите на извънмагазинен обмен размяната може да се реализира в голямото разнообразие от алтернативни точки на контакт между участниците и многократно по-широки възможности на измеренията на удобството, изразени като време, продуктово многообразие, ценови условия и пр.

\section{1. Изследване на търговията на дребно извън търговски обекти в област Варна}

Търговията на дребно извън търговски обекти (ТДИТО) в област Варна е предприемаческа инициатива, демонстрираща нарастващи икономически параметри на активните предприятия. Едно от доказателствата за това е увеличението от над 15 пъти в броя на опериращите икономически агенти в тази стопанска дейност (вж. табл. 1). Най-голям абсолютен прираст на годишна база е отчетен през 2012 г., когато само за 12 месеца броят на работещите търговски оператори в областта се увеличава със 133 нови фирми. Същевременно, ако изключим минималното намаление през 2006 г. спрямо 2005 г., за всички останали години броят е неизменно растящ, което демонстрира притегателната сила и неусвоеният стопански потенциал на извънмагазинната търговия.

Таблица 1. Основни показатели на тьрговията на дребно извън търговски обекти в област Варна по години на периода 2004 - 2016 г.

\begin{tabular}{|c|c|c|c|c|c|c|c|c|c|c|}
\hline \multirow[b]{2}{*}{ Год. } & \multicolumn{10}{|c|}{ Показатели } \\
\hline & $\begin{array}{c}\text { Брой } \\
\text { пред- } \\
\text { приятия }\end{array}$ & $\begin{array}{c}\text { Брой } \\
\text { заети } \\
\text { лица }\end{array}$ & $\begin{array}{c}\text { НПП в } \\
\text { хил. лв. } \\
\text { ср. на } \\
\text { едно } \\
\text { пред- } \\
\text { приятие }\end{array}$ & $\begin{array}{c}\text { нПП в } \\
\text { хил. лв. } \\
\text { ср. на } \\
\text { едно } \\
\text { лице }\end{array}$ & $\begin{array}{c}\text { ПОД в } \\
\text { хил. лв. } \\
\text { ср. на } \\
\text { едно } \\
\text { пред- } \\
\text { приятие }\end{array}$ & \begin{tabular}{|c|} 
ПОД в \\
хил. лв. \\
ср. на \\
едно \\
лице
\end{tabular} & \begin{tabular}{|c|} 
РОД в \\
хил. лв. \\
ср. на \\
едно \\
пред- \\
приятие
\end{tabular} & $\begin{array}{c}\text { РОД в } \\
\text { хил. лв. } \\
\text { ср. на } \\
\text { едно } \\
\text { лице }\end{array}$ & $\begin{array}{c}\text { Равнище } \\
\text { на РОД в } \\
\%\end{array}$ & $\begin{array}{c}\text { Ефективност } \\
\text { на база } \\
\text { ПОД/РОД в } \\
\%\end{array}$ \\
\hline 2004 & 1334 & 2631 & 31,263 & 12,375 & 31,263 & 12,375 & 28,289 & 11,198 & 90,5 & 110,5 \\
\hline 2005 & 1326 & 7111 & 32,830 & 15,701 & 32,830 & 15,701 & 32,471 & 15,530 & 98,9 & 101,1 \\
\hline 2006 & 1266 & 2185 & 49,331 & 20,792 & 49,971 & 21,062 & 46,443 & 19,575 & 92,9 & 107,6 \\
\hline 2007 & 1358 & 2267 & 62,431 & 26,949 & 62,967 & 27,180 & 57,608 & 24,867 & 91,5 & 109,3 \\
\hline 2008 & 1878 & 3542 & 61,915 & 37,455 & 63,007 & 38,115 & 60,073 & 36,341 & 95,3 & 104,9 \\
\hline 2009 & 2418 & 4453 & 26,854 & 20,480 & 28,436 & 21,686 & 28,829 & 21,985 & 101,4 & 98,6 \\
\hline 2010 & 2513 & 4403 & 18,536 & 16,991 & 19,575 & 17,944 & 20,384 & 18,686 & 104,1 & 96,0 \\
\hline 2011 & 2699 & 4757 & 23,333 & 18,721 & 24,006 & 19,262 & 23,409 & 18,783 & 97,5 & 102,6 \\
\hline 2012 & 3574 & 5519 & 18,975 & 16,474 & 19,360 & 16,808 & 18,015 & 15,641 & 93,1 & 107,5 \\
\hline 2013 & 4089 & 5910 & 38,807 & 28,683 & 39,338 & 29,076 & 34,602 & 25,576 & 88,0 & 113,7 \\
\hline 2014 & 4454 & 6185 & 28,473 & 25,133 & 29,770 & 26,278 & 26,194 & 23,122 & 88,0 & 113,7 \\
\hline 2015 & 4885 & 6597 & 24,754 & 25,548 & 25,803 & 26,631 & 22,828 & 23,560 & 88,5 & 113,0 \\
\hline 2016 & 5527 & 8237 & 37,257 & 35,958 & 38,629 & 37,281 & 34,590 & 33,384 & 89,5 & 111,7 \\
\hline
\end{tabular}

Сходно е общото движение и по показателя, отчитащ броя на заетите лица, което обаче има и своите две специфични особености. Едната характеристика е свързана с побавното нарастване в сравнение с броя на опериращите предприятия, което от най-ниската 
отчетена величина - 96 лица към началото на изследователския период (2004 г.), достига до своето най-високо значение от 602 бр. заети през 2016 г. или общо над шест кратно увеличение (627\%). Другата характеристика е цикличността в развитието на броя на заетите в тази икономическа дейност, която в рамките на периода 2004-2016 г., отбелязва две шокови редукции, първата през 2010 г. и втората по-продължителна през 2014 и 2015 години. Отчетеното свиване в броя на заетите лица в ТДИТО в сравнително кратки срокове е обърнато като посока на развитие, при което относително бързото наваксване е отчетлив сигнал, че тази стопанска дейност има своята директна зависимост от кризисните процеси в местната, националната и глобалната икономика. И ако в други бизнеси съществуват резерви за овладяване на икономическите сътресения, то при продуктовия обмен свиването в продажбената дейност непосредствено и в кратки срокове съобразно общото и трудовото законодателството, може да редуцира необходимостта от човешки ресурс, независимо от неговата професионална компетентност и работен опит. Валидно е и обратното при икономически растеж ТДИТО реагира незабавно, дори изпреварващо на възникващите пазарни възможности. Същевременно в сила е разбирането, че за разлика от други специфични икономически дейности в тьрговията на дребно има изключително широки и почти неограничени възможности по отношение на персоналните трудови характеристики на привличания от пазара човешки ресурс. Това е така, защото тя създава заетост за лица с разнообразна трудова практика и професионална пригодност.

Икономическата рационалност обвързва промяната в броя на функциониращите на пазара стопански агенти да се съпътства и с изменение на заетите лица, но в началото на изследователския период тази логика не се е реализирала и освен това едновременността в развитието на тези бизнес показатели протича с различна интензивност във всеки отделен подпериод. Така например, през 2005 г. на едно предприятие се падат средно над 5 заети лица (5,4 бр.), докато през 2016 г. този показател се понижава до почти 2 лица (1,5 бр.). Тази промяна е сигнал за оптимизирането на търговския процес и то по отношение на неговата автоматизация и дигитализация. Отделно от това е ясен белег за доминирането на тази стопанска дейност от микро икономически агенти с относително малък брой на заетите лица. Това еднозначно определя масовия облик на бизнеса на търговията, осъществявана извън магазини, като микро предприемачество с широки възможности за индивидуална стопанска инициатива и самостоятелна заетост.

Аналогична е природата и на връзката между заетите лица и реализираните нетни приходи от продажби, където увеличението на продажбения икономически ефект би следвало да предизвиква решения за нарастване на заетите лица в дейността и обратно, но има години, когато показателят за заетостта изпреварва и други години, в които изостава спрямо промените в продажбените резултати. Така например, през 2009 г. на фона на разрастващите се кризисни ефекти на глобалната стопанска криза в икономическата дейност на търговията на дребно извън магазини е било предизвикано понижение на продажбите с 33\% от 6067 хил. лв. на 4054 хил. лв. Тази негативна промяна не се е възпроизвела при състава на заетите лица, където е отчетено повишение от 162 бр. на 198 бр. или темп на прираста от 22\%. Алтернативен ход на развитие е регистриран през 2013 г., когато при темп на растеж на продажбите от 238\% или от 6375 хил. лв. на 15173 хил. лв., заетостта се увеличава едва с 137\% или от 387 лица пред 2012 г. се достига до 529 работещи в тази дейност през 2013 г. Въпреки своята слаба проява е интересна реакцията на агентите на обмена през 2015 г., когато продажбите (12 748 хил. лв.) се задържат на минимално повисоко равнище от предходната 2014 г. (12 642 хил. лв.) или относително нарастване от 100,8 
\%. Същевременно това е разчетено като сигнал за слаба, понижаваща корекция на заетите лица и тяхното редуциране от 503 бр. на 499 бр. (99,2\%). Следователно, незначителните промени в икономическите ефекти на ТДИТО, предизвикват минимални корекции по отношение на използвания трудов ресурс, докато съществените промени, често пъти провокират свръх оптимистични реакции на предстоящите пазарни възможности или заплахи в краткосрочен времеви хоризонт. Ефективността на тези решения е видима през повечето от годините на периода, когато производителността на труда, измерена като нетни приходи от продажби средно на едно заето лице, нараства. Обратно, през 2009, 2010, 2012 и 2014 г. понижението в показателя за резултатността на труда е неблагоприятен ефект, предизвикан от по-бавното намаляване на броя на заетите лица при свиване на продажбите (2010 и 2014 г.), от нарастването на броя на заетите при понижаващ се общ обем на продажбите (2009 г.) и изпреварваща заетост в сравнение с увеличението, регистрирано при продажбите (2012 г.). Практическата реализация на всяка от тези ситуации ясно демонстрира адаптиращото поведение на търговията на дребно, осъществявана извън магазини, по отношение на пазара на труда и системните корекции в броя на ангажирания човешки ресурс в търсене на рационалност за неговото използване и оптималност на целия икономически процес. Тук все по-голяма значимост придобива дигитализационната трансформация на търговията на дребно и все по-широкото навлизане на нови технологии и автоматизация в търговския процес. Въпреки това, човешкият фактор продължава да бъде водещия за икономическата и социална успешност на търговския бизнес, където уменията на специалистите по персонални продажби може да бъдат източник на сериозни конкурентни предимства.

При групата на показателите, посочващи използването на трудовия фактор, откриваме още една обща закономерност, че нетните приходи от продажби средно на едно лице, приходите от дейността средно на едно лице и разходите за дейността средно на едно лице отчитат най-висока оценка през 2008 г., а най-ниска към началото на периода през 2004 г. Регистрирането на двете критични стойности и трикратното им разминаване в първата половина на периода е сигнал за развитие на ТДИТО по посока в търсене на системна оптималност от трудовия ресурс. Същевременно на годишна база най-съществено е относителното нарастване на показателите през 2013 г., когато нетните приходи от продажби средно на едно лице се повишават с 174,1\%, при приходите от дейността средно на едно лице със $173 \%$ и разходите за дейността със 163,5\%, което демонстрира умението на бизнеса да управлява заангажирания човешки фактор, посредством по-слабото му нарастване.

В развитието на показателя нетни приходи от продажби, дефлиран с индекса на потребителските цени към началото на изучавания период, кризисният процес е добре отличим със своето настьпване през 2008 г., едновременно с неговото проявяване в световното стопанство. Регистрираното понижение на продажбите от извънмагазинната търговия е $33,2 \%$, което на фона на понижението при продажбите в търговията на дребно в България от $11 \%$ е сигнал за глобалния профил и външнотърговската насоченост на обменните процеси в търговията на дребно извън търговски обекти. Задълбочаването на този първи продажбен шок продължава и през 2009 г., когато нетните приходи от продажби по съпоставими цени се свиват с допълнителните $29,6 \%$, което е овладяно като негативен процес едва през 2010 г., когато на годишна база се достига до обем на търговията на ниво по-високо от поставилата началото на кризата в България 2008 г. Последвалият кратък период на възстановяване е отново застигнат от второ кризисно смущение през 2014 г., което е по-слабо изразено и сравнително бързо овладяно, нещо повече в края на периода 2016 г. е 
отчетен годишен ръст от $169,8 \%$, довеждащ ТДИТО в област Варна до рекорден обем на продажбите, които се равнява на 21646 хил. лв. по сьпоставими цени на 2004 г. $=100$.

В рамките на по-голямата част на периода на изследване от 2004-2016 г. показателят равнище на разходите се задържа под 100\%, но през 2009 и 2010 г. той е с оценки от 101,4\% и $104,1 \%$, което е индикация за усилията за овладяване на кризисната контракция. Поддържането на показателя на ниско равнище от под 90\% през подпериода 2013-2016 г. демонстрира постигнатата икономическа рационалност на бизнес дейността на ТДИТО, при което нетните приходи от продажби превишават величината на направените разходи. Реализацията на подобно състояние на ефективно управление на разходите във фирмите от икономическата дейност на извънмагазинната търговия на дребно е сигнал за по-доброто използване на материалните ресурси и по-рационално натоварване на трудовия фактор и се явява конкурентно предимство на цялата икономическа дейност.

При показателите, отчитащи концентрацията в ТДИТО, са отчетени най-високи значения през 2008 г., единствено при нетните приходи от продажби средно на едно предприятие това е било регистрирано една година по-рано през 2007 г. Еднозначно времевото проявление на тези рекордни стойности потвърждава икономическата значимост на членството на страната в ЕС и предизвиканите от това благоприятни стопански ефекти за бизнеса. Друг важен момент е, че по отношение на минималните значения на показателите, тези средно на едно предприятие не са постигнати към началото на периода, а на един покъсен етап за нетните приходи от продажби средно на едно предприятие през 2010 г. (18,536 хил. лв.), при приходите от дейността средно на едно предприятие през 2012 г. (19,360 хил. лв.) и при разходите за дейността средно на едно предприятие 2012 г. (18,015 хил. лв.). Подобно състояние се е предизвикало от комбинирането на два процеса, единият е кризисното свиване на стойностните показатели, а другият е разрастването на натуралния показател на икономическата дейност, свързан с броя на новосъздаваните предприятия за търговия на дребно извън магазини.

В обобщение, направеният преглед на развитието на основни икономически показатели от дейността на предприятията от ТДИТО разкрива атрактивността на извънмагазинните форми на търговски бизнес за предприемаческа активност в област Варна. Разширяващите се стопански индикатори са доказателство за положителните промени, съпьтстващи традиционните и нови форми на продуктов обмен, осъществяван извън търговски обекти и са доказателство за конкурентните позиции, които той заема на пазара. Разбира се, тук приемаме специфичните особености на методологията на националната статистика, която определя принадлежността на икономическите агенти към дадена дейност според нейния принос да създава най-голям дял в добавената стойност, създавана от дейността на бизнес единицата. Това предизвиква ситуация, при която в условията на интензивна пазарна конкуренция, икономическите агенти прибягват до едновременно прилагане на разнообразни форми на обмен извън търговски обекти наред с традиционните форми на магазинна размяна, което е част от осъществяваните от тях мултиканални и омниканални пазарни стратегии. Подобен подход отчасти влиза в противоречие с подхода за класифицирането в определен клас икономическа дейност на бизнес единиците, което трябва да бъде еднозначно определено, според доминиращата в създаването на добавена стойност дейност. Това означава, че определени икономически ефекти на извънмагазинните форми на търговия остават извън специфичната статистическа отчетност на тази икономическа дейност с код 47.9 „Търговия на дребно извън търговски обекти“ по КИД-2008, което е обусловено от подхода за класифицирането на икономическите субекти, а от там и на 
техните стопански показатели, които се идентифицират в алтернативни наименования и кодове на изградената йерархична система на класификацията на икономическите дейности.

В обобщение допускаме, че общото благоприятно развитие на ТДИТО протича с различна интензивност при отделните форми на извънмагазинен обмен, като дори при някои е възможна и редукция на стопанската активност. Основното ограничение на подобно задълбочаване на изследването е, че официалната статистика не предоставя данни с подобна структура, която да ги идентифицира като отделни форми на търговия. Въпреки това, протичащата дигитализационна промяна в тьрговския бизнес може да бъде източник на адаптираща промяна за повечето от тях, така например интерактивният хоумшопинг, достигащ до крайния потребител посредством умни (smart) телевизионни приемници, други умни устройства и дори миграцията му в онлайн среда; създаването на виртуални електронни каталози и технологията на чатбота при директните продажби; интелигентните вендинг машини и др.

\section{2. Възможности за бъдещо развитие}

В краткосрочен времеви хоризонт основното направление за усъвършенстване на извънмагазинната търговия на дребно е във връзка с подобряване на организацията и технологията на доставка в рамките на деня в обхвата на населеното място, но с постепенно разрастване и налагане на подходяща организация и подобен стандарт за целия регион (област). Пренасянето на конкурентната борба при електронната търговия и другите форми на ТДИТО е в полето на условията на доставката като подобряващата се стойност и/или за сметка на изпращащата страна, редуциране на сроковете за доставка, предлагане на форми на допълнително куриерско обслужване, съвместяване на финансови операции, свързани с продажбата, покриване на рискове, посредством включване в цената на куриерската услуга на застрахователна премия по желание на клиента и др., което ще позволи чрез иновативно поведение успешните компании да се отличат като лидери от последователите на пазара. Тук възможните промени са свързани с подхода за пълната интеграция на дейността на куриерската компания с тази на търговията на дребно извън магазини, което може да се реализира или като единна собственост на двата бизнеса или чрез аутсорсинг и инсорсинг на куриерската услуга. Обединяването на търговската дейност с тази на куриерската компания ще позволи на извънмагазинните агенти на обмена да управляват по-умело своите стокови запаси и да минимизират тяхното поддържане до степен на транзитна продуктова реализация (например посредством dropshipping). Прилагането на способа за изпълнение на доставката в рамките на деня може да се осъществи при условие на подадени поръчки до определен час или чрез доставка във фиксиран от потребителя ден, час и място. Последното може да се реализира до предпочитани от клиента локации като автоматични пощенски станции, работещи в непрекъснат режим 24/7, адреса на местоживеене, месторабота или всяка друга определена от клиента локация. Употребата на този подход „ще позволи на клиента да пазарува когато, както и където пожелае“ (Zoller, 2016, p. 8). Същевременно посредством дигитализационната трансформация в куриерската дейност се осигуряват широки възможности за проследимост в реално време на пратката и непрекъснато управление на организацията и технологията на нейната доставка.

Алтернативна възможност е развитие на подхода click-and-collect (онлайн поръчка и вземане от желано място), посредством разширяване на предлагания асортимент, опции за доставка в рамките на деня в желано от потребителя място за вземане на поръчката и др. Електронните канали за продуктово разпространение позволяват широки възможности за 
оползотворяване на по-добрите условия на размяната, както чрез механизмите за продуктово и ценово сравнение, електронните инструменти и средства за персонализиране на тьрговската оферта, детайлно изучаване на потребителската лоялност, по-висока ефективност на насочваните към промоции ресурси, посредством индивидуализиране спрямо потребителя на маркетинговите инструменти за привличане на купувачи, стимулиране на продажбите, клиентската лоялност и други икономически инструменти.

\section{Заключение}

Без съмнение електронните форми на търговия на дребно извън търговски обекти ще продължат своето позитивно развитие, което може да бъде повлияно от фазите на икономическия цикъл на локално, регионално, национално или глобално ниво, но несъмнено ще бъде обвързано с търсенето на подобрени алтернативи, така че потребителското търсене да бъде все по-пълноценно предвидено, стимулирано и задоволено. Перспективите на протичащата дигитализационна трансформация ще предоставят като фактор, разширяването на обменните процеси в цифрова среда, където крайните потребители, като членове на информационното общество, могат да получат по-пълноценно информационно обезпечение и да открият разнообразни възможности за по-добри условия на размяната и полезност от алокацията на разполагаемия ресурс.

\section{References}

1. eMarketer inc. (2016) Retail Ecommerce Sales Worldwide, 2015-2020 (trillions, \% change and $\%$ of total retail sales). [Online] Available from: https://www.emarketer.com/Chart/RetailEcommerce-Sales-Worldwide-2015-2020-trillions-change-of-total-retail-sales/194275 [Accessed 12/07/2019].

2. eMarketer inc. (2018) Retail Mcommerce Sales Worldwide, 2016-2021. [Online] Available from: https://www.emarketer.com/chart/215111/retail-mcommerce-sales-worldwide-20162021-trillions-change-of-ecommerce-sales [Accessed 12/07/2019].

3. Eurostat. (2019) METADATA. Statistical Classification of Economic Activities in the European Community, Rev. 2 (2008). [Online] Available from:

https://ec.europa.eu/eurostat/ramon/nomenclatures/index.cfm?TargetUrl=LST_NOM_DTL\&Str Nom=NACE_REV2\&StrLanguageCode=EN\&IntPcKey=18512264\&StrLayoutCode=HIERAR CHIC [Accessed 12/07/2019].

4. Zoller, E. (2016) The Future of E-commerce: The Road to 2026. London: Ovum. 